\title{
COMPUTER AND EXPERIMENTAL SIMULATION OF BIOMASS PRODUCTION USING DRUM CHIPPER
}

\author{
Krajnc, M.* \& Dolsak, B. ${ }^{* *}$ \\ *KGS Krajnc d.o.o., Vinicka vas 4, 2230 Lenart v Slovenskih Goricah, Slovenia \\ ** University of Maribor, Faculty of Mechanical Engineering, Smetanova 17, 2000 Maribor, Slovenia \\ E-Mail:mitjakr@gmail.com; bojan.dolsak@um.si
}

\begin{abstract}
When producing wood chips using a drum chipper, several material, construction, and technological parameters that influence this process need to be observed and controlled. The correct choice of optimal parameters during the production of wood chips is reflected in the amount of used energy deposited within the wood mass. The results of monitoring the thermal characteristics of individually different kinds of wood chips show that biomass using rougherstructured wood fibers is more suitable for larger systems. Dust particles within the wood fractions are undesirable despite however welcome the consistent form and size structures of the wood chips are. Based on the results of computer simulations, real measurements, and testing during the production of wood chips, we found discrepancies between the predicted and actual characteristics of the desired outputted wood fuel. The reasons for the determined discrepancies are stated and commented on.

(Received in April 2012, accepted in November 2012. This paper was with the authors 1 month for 2 revisions.)
\end{abstract}

Key Words: Biomass, Drum Chipper, Production Optimisation, Influential Parameters, Simulation Model

\section{INTRODUCTION}

The energy potentials of most organic substances, commonly known as biomass, are becoming more important when considering the inconsistent and expensive supplies of fossil fuels. Biomass is suitable for generating both thermal and electrical energies. Energy generated from naturally renewable sources is ecologically undisputed and largely contributes to generating primary energy. Using energy products such as wood biomass could also enable partial energy independence for certain countries that fulfil or even exceed their economic needs for biomass sources. Slovenia is one of these countries.

In wood biomass, wood chips are understood as particles of chipped wood. Wood chips are from mechanically ground, milled, and chopped types of wood of inferior quality up to the size of $100 \mathrm{~mm}$, usually produced from smaller diameter wood, wood of inferior quality or wood remains. The quality of wood chips is defined according to the quality of the inputted raw material, and the production technology. Production technology, size levels, and the forms of grinding in the case of wood chips, have to be adapted to the demands against possible combustible installation [1].

In the spirit of environmental protection and sustainable development, a research challenge emerged for discussing the economic and ecological aspects of wood biomass production, and the quality of the generated product, as the alternative to other fuels, even if they are not fossil [2]. All three aspects namely depend on the correct choice of a suitable production technology, the selecting of suitable raw materials, and the economic situation on the market. The efficiency of appropriately chosen and monitored technology is shown in the quantity of energy, which is stored within the wood mass [3]. 
When producing wood chips using a mobile drum-chipper, many material, constructional, and technological parameters can be can encountered. All these parameters affect the quality, economy, and efficiency of wood chip production. However, computer configuration alone of the chipper for the desired fraction is insufficient. The real production of wood chips is composed of many other influential parameters that are hard to manage. Thus, the previously controlled production of wood chips was based mostly on practical experience and testing. Since this is a complex field, where the management of a greater number of partially interdependent parameters is needed, such an approach is unsuitable and usually does not lead to the desired results [4].

\section{MATERIALS AND METHODS}

Within the framework of the research work presented in this paper, the differences between the analytically-set technological and constructional parameters of the chipper for the desired fraction, which originated from computer simulations, and the actual real production output fraction regarding the wood chips were researched.

\subsection{Wood biomass production}

The inputted raw material characteristics vary for different types of wood. Wood can be hard, soft, moist or dry, and of different structures [3].

A chipper is a machine for processing circular wood and producing wood chips. Chippers are, in many cases, adjuncts on driving tractors (Fig. 1), or can be placed on a truck. There are many kinds of chippers. The most common are drum chippers that are bigger and more powerful than disc chippers, and easily process circular wood and also wood remains. Therefore, drum chippers are mostly used for generating wood biomass for energy purposes.

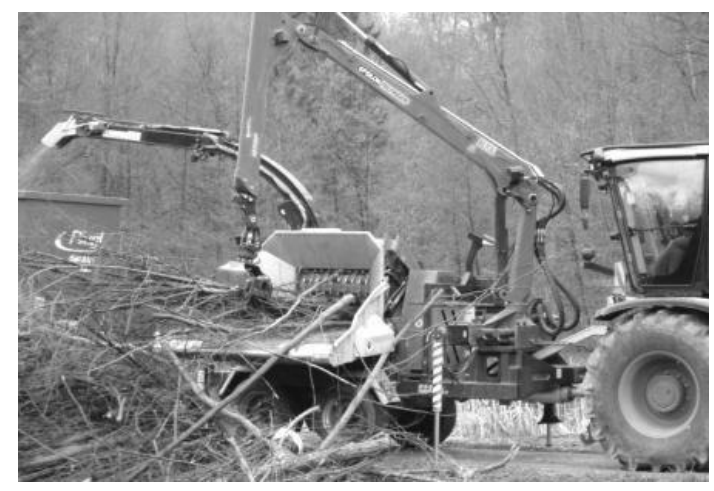

Figure 1: Drum chipper Mus Max WT 11.

The drum consists of a steel cylinder with 12 or more knives set in tangential positions. Chip size is more heterogeneous; however, it can be defined as a net (sieve) which filters chips of defined sizes. The knives have to be changed every 50-100 tons (when working with hard wood) and every 200-300 tons (when working with soft wood).

The main chipper units are the feeding unit, chipping unit, and output unit (Fig. 2). The raw material (wood) travels from the feeding unit to the chipping unit via a transporter belt. The chipping aggregate chips the wood into smaller pieces (chips). This procedure is executed by a spinning drum with knives along its rim. The chipping drum is heavy and therefore operates with a large moment of inertia. The knives spin in a counter-direction to the counter knife, which is set directly by the chipping drum itself. The counter knife acts as a counter blade and the chips fall through the sieve. The sieve is positioned directly below the chipping 
drum. The chips are then transported from the interior of the machine to the outside with the help of ejecting devices. The transporting of the chips runs through screw nails to the wind turbine which blows the chips onto the transportation vehicle.

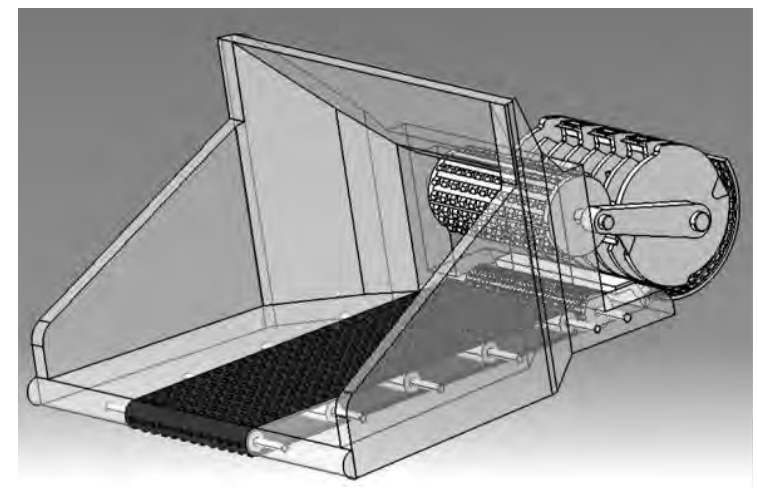

Figure 2: Computer model of the main drum chipper's parts.

The mobile chipper Mus Max WT 11 was used during the experiment. It was run on a Cardan shaft using a Claas Xerion 3800 tractor. The Mus Max WT 11 chipper can process wood with diameters of up to $\varnothing 750 \mathrm{~mm}$.

In the past, some research was carried out in the field of determining the influence of parameters during the production of wood chips. Substantial research has also been done mostly on the relation between the desired output capacity and the fuel consumption [5-7]. Consumption was lessened by increasing the output size fraction [4, 6]. It has also been determined that in comparison with the energy, which is stored within the wood mass we produce [5], less than $2 \%$ of fossil fuel energy is used for the production of wood chips. There is, of course, a tendency to reduce the production costs of one product unit. Researchers have also discussed the individual influences of those technological parameters that occur during wood chip production. The main focus was on the influences of individual blades' sharpness on fuel consumption, productivity, and any change in the output fraction $[4,6]$. The quality of the produced wood biomass largely depends on the process of chipping wood [8]. Wood chips, produced by a drum, disc or snail chippers can be differentiated between mostly regarding form and size structure [9], considering measurement possibilities [10]. In the process of wood chipping many factors occur that influence the process of producing wood biomass $[9,11]$. Here, we cannot exclude the human factor, which greatly influences the productivity of the process and any delays [12-14].

All the consulted articles discussed the research of influence parameters, but none included a comparison between the computer simulation of the configuration and the chipper function for the desired fraction and the actual fraction itself.

\subsection{Monitoring the thermal characteristics of wood chips}

Different wood fractions store different usable thermal energies [1]. In order to better understand the influence of an individual parameter on the wood fuel the thermal characteristics of different input wood biomasses were monitored. Monitoring was executed using an Urbas combustion installation (bio boiler) with a power of $3.500 \mathrm{~kW}$ using the attached mechanical equipment, which also controls the bio boiler in the boiler room. The following characteristics were monitored (Fig. 3): number of turns of the primary ventilator, temperature of the bio boiler firebox, negative pressure of the firebox firing place, momentary bio boiler power, produced thermal energy of the bio boiler, quantity of oxygen in the flue gases, isotopic temperature of the bio boiler water, and momentary air temperature. 
Monitoring was executed on the basis of known material parameters, which were: wood type, wood fibers' size class, form constancy and homogeneity of the wood fibers, wood fiber cleanliness, percentage of dust particles, and moisture of the wood fibers.

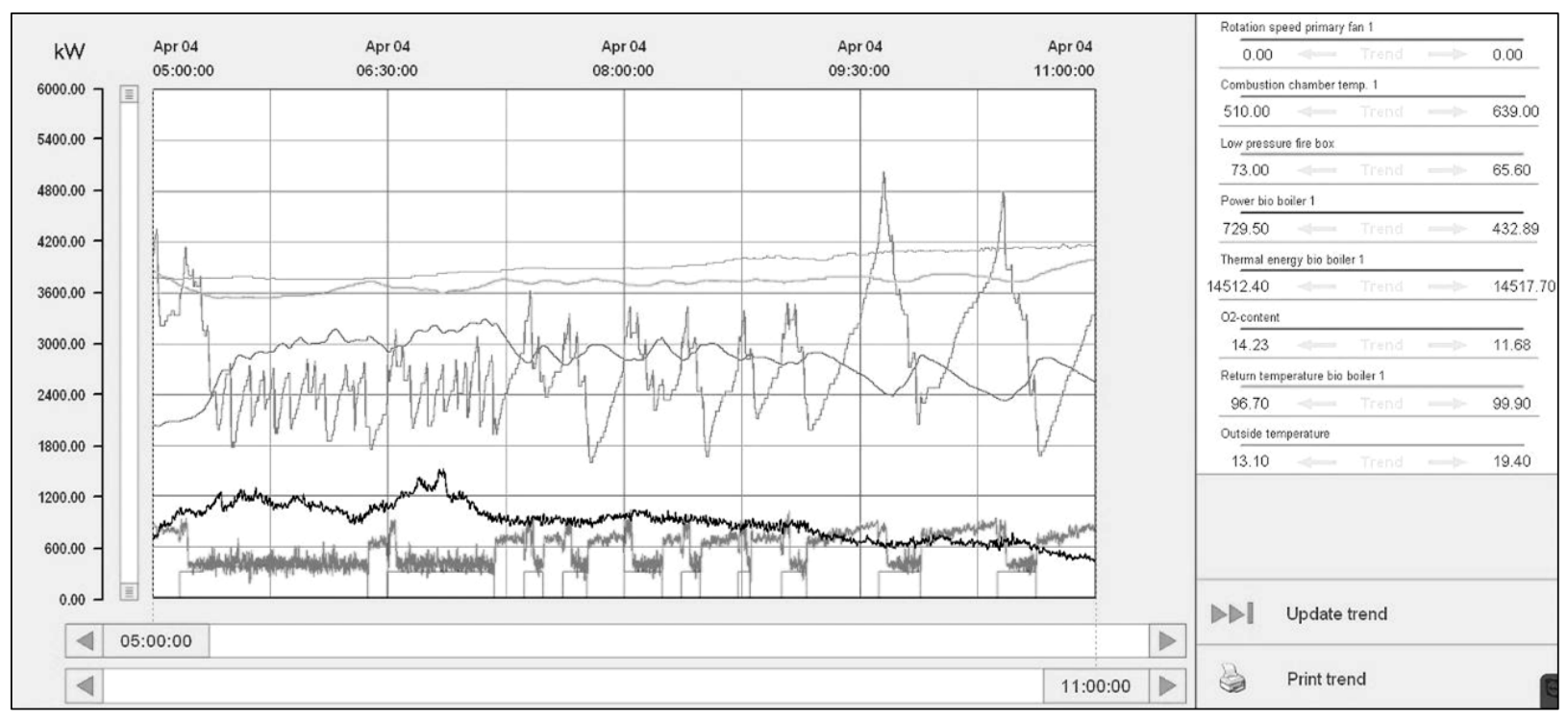

Figure 3: Monitoring thermal characteristics within a defined time period.

Monitoring the thermal characteristics determined the following conclusions when considering wood biomass suitable for larger systems (listed in order of importance, starting with those to which the production process has the greatest influence):

1. Wood chips should have a rough structure (G100).

2. Wood chips should have a uniform size and form structure as much as possible.

3. Biomass should contain as small number of dust particles as possible.

4. Clean biomass produces better thermal utilization.

5. Dry biomass ( $<35 \%$ of moisture) has better combustibility, which depends greatly on the inputted raw material.

These recommendations led to determining the most desirable characteristics of wood fuel that drum chipper needs to ensure by proper configuration. The usable thermal energy of a certain wood fraction can also vary by up to $10 \%$ [15-16].

\subsection{Defining the influential parameters}

Three groups of complex parameters, technological, constructional, and material, could be defined during the production of wood biomass. The technological and constructional parameters relate mostly to the chipper (Fig. 2) and the material to wood biomass as an input and output raw material [7].

The main technological parameters of the chipper are the following: the speed of the feeding table transport band, the number of turns of the upper and lower pulling cylinders, the upper cylinder pressure on the input material, the number of spins of the chipping drum, the distance of the knives from the counter blade, the spinning speed of the discharge fan, and the quantity of conveyed air. Technological parameters are easier to change as the changes can also be executed during the process $[9,17,18]$.

The constructional parameters are somehow harder to change, since this would require modification of the individual mechanical parts or units [19]. The constructional parameters of the drum chipper are the following: form and sizes of the points on the feeding table, the size (diameter) of the upper and bottom pulling cylinder, form and sizes of points on the 
upper and bottom pulling cylinder, chipping drum diameter, chipping drum weight, number and positions of knives in the chipping drum, the chipping knives' sharpness angles, counter blade sharpness, sizes and form of sieve rifts, the form of the discharge fans etc. All these parameters were taken into consideration when creating computer model of the chipper to perform further simulations. It is of course possible to also consider a total change in the manner of producing wood chips which, consequently, would radically change the construction of the whole device [20].

The material parameters of the input material such as wood moisture, forms of the raw material (branches, circular wood, ...), type of wood (soft, hard), etc. would be hard to influence since in practice the material that is currently at disposal is used [3]. However, these parameters can be well-defined and monitored.

Following the cross-linked simulation theory [21] a hypothesis was formed that for each different raw material there exist an optimal combination of technological and constructional parameter configurations on the chipper, which guarantees the desired output chip fraction during real production.

\subsection{Computer simulation of influential technological parameters}

In order to define the connection between chipper configuration for a desired fraction and the real output chip fraction, it was decided to monitor only the technological parameters on the chipper. Varying constructional parameters would interfere with the machine's construction and might cause eventual errors during its functioning.

Practical experiences in production of wood biomass show that the following three technological parameters play the most important roles in defining the characteristics of the outputted wood chips:

- the speed of the inputted raw material feeding,

- the number of the main chipping drum spins,

- the sizes of the sieves under the main chipping drum.

For feeding the inputted material the speed of the feeding table, which is synchronized with the speeds of the upper and lower pulling cylinders (Fig. 4, left) could be changed. It is also possible to change the speed of the main chipping drum spins (Fig. 4, middle). The number of spins could be changed by varying the number of spins on the tractor's drive shaft. By changing the number of chipping drum spins and the speed when feeding the raw material, one could obtain different sizes and forms of wood fibers. Different forms and sizes of openings in the sieves under the main chipping drum (Fig. 4, right) can also be used. This would only enable the defined size and form of the wood fiber structure to fall through.
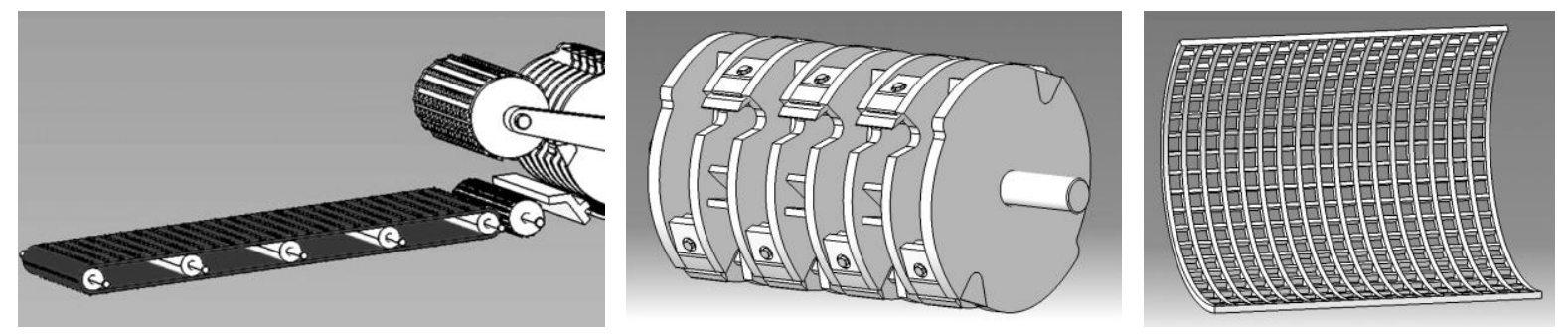

Figure 4: Feeding table with pulling cylinders, chipping drum and sieve.

For defining individual analytical technological parameters, Catia V5 R20 software was used for simulating simplified wood fiber production process. By using the DMU Kinematics working environment, the output size of the wood fibers was defined in relation to the material transfer speed and the number of main chipping drum spins. All important parts of 
the drum chipper were modelled and assembled into kinematic chain with restraints defined in terms of boundary conditions. Some special cases were also considered. For example, the chipping knives on the chipping drum were set symmetrically in pairs. This means that one chipping drum spin cut the inputted material twice. However, according to the decision that this experiment will serve as a basis for further research and should thus not be too complex, the friction and contact effects were not taken into consideration. The wood was also considered as an ideal material with no resistance to transformation.

A minimum spin number of $450 \mathrm{~min}^{-1}$ of the main chipping drum is needed for a normal functioning of the chipper. The maximum number of possible chipper spins is $560 \mathrm{~min}^{-1}$. For the simulation presented here three groups of spin numbers 450, 500, and 550 were chosen. The maximum speed of the input material movement was $0.95 \mathrm{~m} / \mathrm{s}$. For the simulation of the process and for determining the size of outputted wood fibers four different input material movements $0.15,0.30,0.45,0.60,0.75$ and $0.90 \mathrm{~m} / \mathrm{s}$ (Fig. 5) were used. The theoretical results for the outputted wood fiber sizes were found after computer simulation (Table I).

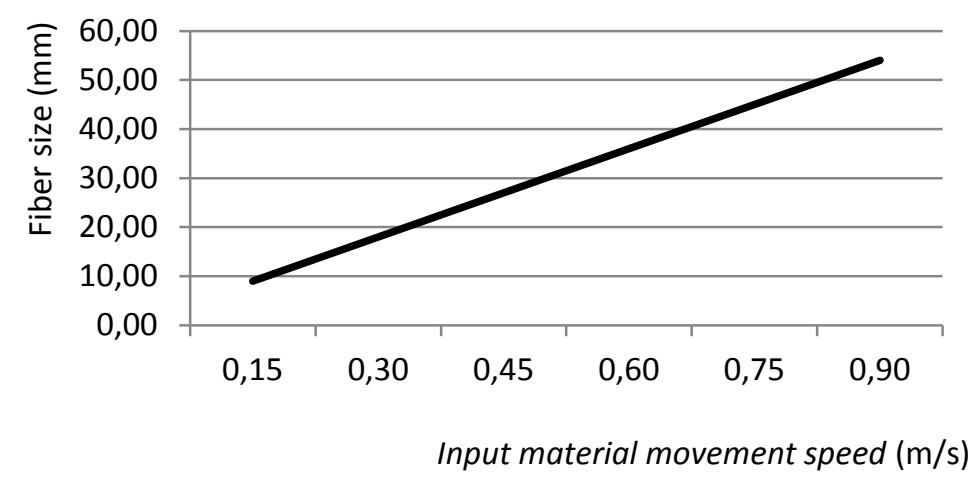

Figure 5: Theoretical fiber size at $500 \mathrm{~min}^{-1}$ at different material movement speeds.

Table I: Theoretical fiber size as a result of the computer simulation.

\begin{tabular}{|c|c|c|}
\hline Spins $\left(\mathrm{min}^{-1}\right)$ & Movement speed $(\mathrm{m} / \mathrm{s})$ & Theoretical size $(\mathrm{mm})$ \\
\hline 450 & 0,15 & 10,00 \\
\hline 450 & 0,30 & 20,00 \\
\hline 450 & 0,45 & 30,00 \\
\hline 450 & 0,60 & 40,00 \\
\hline 450 & 0,75 & 50,00 \\
\hline 450 & 0,90 & 60,00 \\
\hline 500 & 0,15 & 9,00 \\
\hline 500 & 0,30 & 18,00 \\
\hline 500 & 0,45 & 27,00 \\
\hline 500 & 0,60 & 36,00 \\
\hline 500 & 0,75 & 45,00 \\
\hline 500 & 0,90 & 54,00 \\
\hline 550 & 0,15 & 8,18 \\
\hline 550 & 0,30 & 16,36 \\
\hline 550 & 0,45 & 24,55 \\
\hline 550 & 0,60 & 32,73 \\
\hline 550 & 0,75 & 40,91 \\
\hline 550 & 0,90 & 49,09 \\
\hline
\end{tabular}

The form and maximum size for the wood fibers was defined by the sizes and forms of the sieve openings. A sieve with $50 \times 50 \mathrm{~mm}$ openings lets through wood fibers with a 
maximum size of $70 \mathrm{~mm}$ (opening diagonal), and all smaller fibers and dust (Fig. 6). The openings' forms (circular, rectangular, square, etc.) defines the wood fibers' forms. In the time of the experiments only sieves with square openings' form were at disposal.

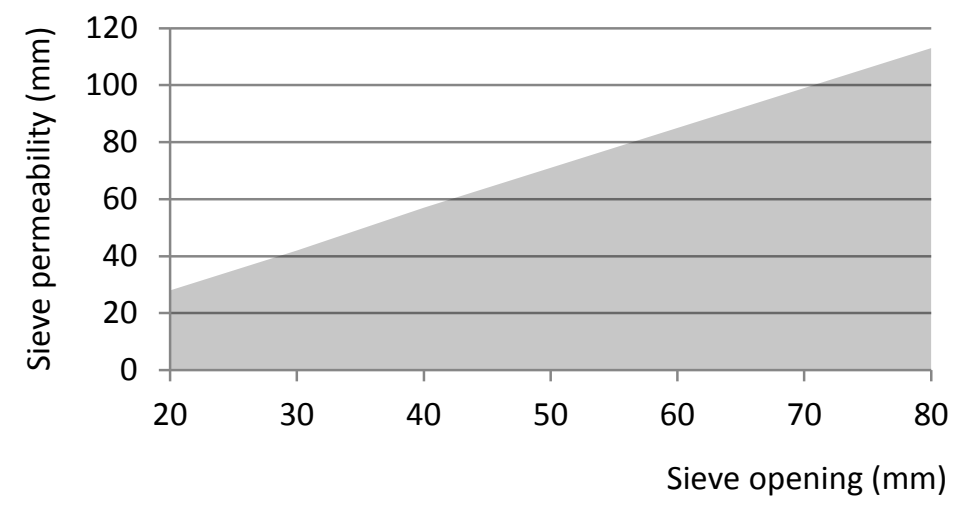

Figure 6: Dependence of the opening's size on sieve permeability.

It is important to emphasize that the results achieved with the help of computer simulation, are only theoretical values without taking into account many actual influential parameters, such as inhomogeneity of wood, different wood moistures, elasticity of the metal materials, delay times [22] etc. For computer simulation a simplified and ideal computer model of the chipper was used and considered ideal circumstances for the process itself. The purpose was to compare the results of such simplified computer simulation with the results of the real-life experiment in order to determine the real impact of the parameters that were not considered in the simulation, before making more complex analysis if needed.

\subsection{Real testing of wood biomass production}

The testing of wood chip production within a real environment was carried out in the year 2012 (Fig. 7, left). Based on known technological chipper configurations, the material parameters of the outputted wood fuel were determined. Hard and dry wood was used as inputted material. Analytical technological parameters, gained during the computer simulation, were set on the chipper. After setting these parameters, the material parameters of the output fraction were defined.

The speed of input material movement and the number of main chipping drum spins were also modified. The same chipper configuration was used during the real testing of wood chip production and during computer simulation. The number of main chipping drum spins was monitored being between 450 and $550 \mathrm{~min}^{-1}$. The input material movement was also monitored in interval from 0.15 to $0.90 \mathrm{~m} / \mathrm{s}$. The sieves with openings of $80 \times 80 \mathrm{~mm}$ were positioned under the main chipping drum.

At the outputted fraction, the following parameters were measured and assessed: the average size of grains as a fraction $(\mathrm{mm})$, the share of constant fraction $(\%)$, the constancy of form and size structure.

\section{RESULTS AND DISCUSSION}

For each individual type of computer determined analytical configuration regarding the chipper technological parameters, the measurements based on nine different combinations of technological parameters were executed. The average grain size from individual fractions was measured for the outputted wood chips. For every measurement, ten similar (more common 
sizes) wood fibers as individual fractions were taken into consideration to calculate an average value. The size for the wood fibers was determined using a calliper gauge. The share of the wood fibers constant fraction was determined using a sieving method, which is the most appropriate procedure for defining the consistency of a fraction [17, 23]. Individual fractions were thus sieved through different sieves with different openings (Fig. 7, right).
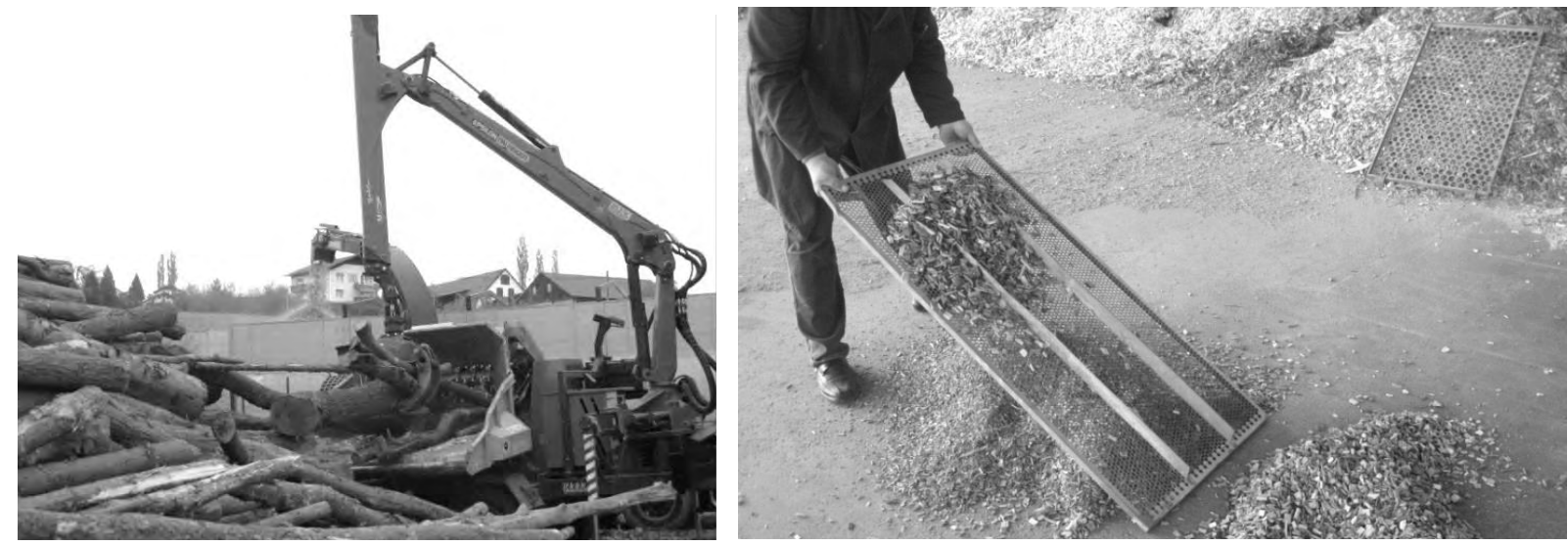

Figure 7: Real testing of wood biomass production (left); sieving analysis (right).

The constancy of the forms and size structures of individual particles was determined optically using the terms good, medium, and bad (Fig. 8 - from the left to the right).

For every chipper configuration (16), three real tests were carried out. Thus, 48 tests were made in total. The medium value of individual results was chosen.
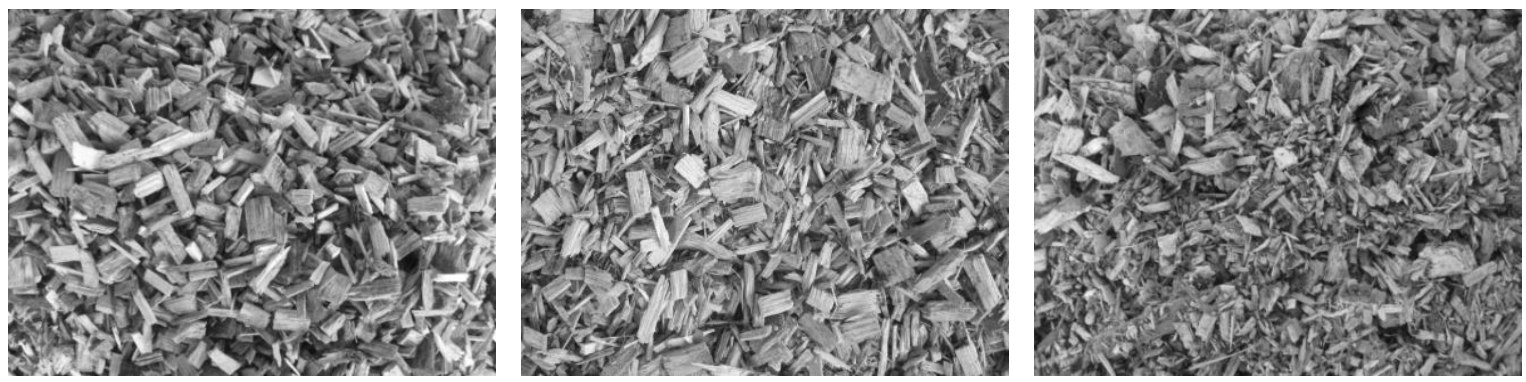

Figure 8: Constancy of the forms and size structures.

\subsection{Results of real measurements}

Table II shows the measurement results used for determining the difference between the individual computer analytical and the working technological parameters.

According to the theoretically-desired output parameters of the wood biomass, the following conclusions were reached on the basis of testing during the real process of wood biomass production:

1. As it can be seen in Fig. 9, the sizes of the wood fibers that were expected according to the results of the computer simulations differ from the actual fraction obtained during the real measurements. For clearer picture, Fig. 9 presents the comparison only at 500 spins of the chipping drum. The circumstances at other two spins observed are similar.

2. It was noticed that smaller inputted material movements produced bigger chips than those theoretically set. Bigger movements produced smaller chips than those set.

3. A bigger share of a constant fraction was produced at a lower number of main chipping drum spins. 
4. A lower number of main chipping drum spins also caused better wood consistency for wood chip form and size structures.

5. A higher number of main chipping drum spins and smaller input material movement produced a higher dust particle share within the wood fraction.

6. Fig. 9 shows that specific inputted material movement speed resulted into the same theoretical and actual size class for the wood chips (intersection point).

7. Non-homogeneity of the input material (wood) caused a bigger percentage of irregular size and form structures at all configurations.

Table II: Real testing measurement data.

\begin{tabular}{|c|c|c|c|c|c|}
\hline $\begin{array}{c}\text { Spins } \\
\left(\mathrm{min}^{-1}\right)\end{array}$ & $\begin{array}{c}\text { Movement speed } \\
(\mathrm{m} / \mathrm{s})\end{array}$ & $\begin{array}{c}\text { Theoretical size } \\
(\mathrm{mm})\end{array}$ & $\begin{array}{c}\text { Average size } \\
(\mathrm{mm})\end{array}$ & $\begin{array}{c}\text { Share of constant } \\
\text { fraction }(\%)\end{array}$ & Structure \\
\hline 450 & 0,15 & 10,00 & 18,20 & 75 & good \\
\hline 450 & 0,30 & 20,00 & 27,60 & 70 & good \\
\hline 450 & 0,45 & 30,00 & 36,50 & 70 & good \\
\hline 450 & 0,60 & 40,00 & 44,20 & 65 & good \\
\hline 450 & 0,75 & 50,00 & 49,80 & 60 & medium \\
\hline 450 & 0,90 & 60,00 & 55,70 & 65 & medium \\
\hline 500 & 0,15 & 9,00 & 16,90 & 65 & good \\
\hline 500 & 0,30 & 18,00 & 23,80 & 70 & medium \\
\hline 500 & 0,45 & 27,00 & 33,60 & 60 & good \\
\hline 500 & 0,60 & 36,00 & 40,50 & 55 & medium \\
\hline 500 & 0,75 & 45,00 & 43,80 & 55 & bad \\
\hline 500 & 0,90 & 54,00 & 49,20 & 50 & medium \\
\hline 550 & 0,15 & 8,18 & 14,70 & 55 & medium \\
\hline 550 & 0,30 & 16,36 & 20,20 & 50 & medium \\
\hline 550 & 0,45 & 24,55 & 26,60 & 50 & bad \\
\hline 550 & 0,60 & 32,73 & 32,10 & 45 & bad \\
\hline 550 & 0,75 & 40,91 & 38,90 & 45 & medium \\
\hline 550 & 0,90 & 49,09 & 46,80 & 50 & bad \\
\hline
\end{tabular}

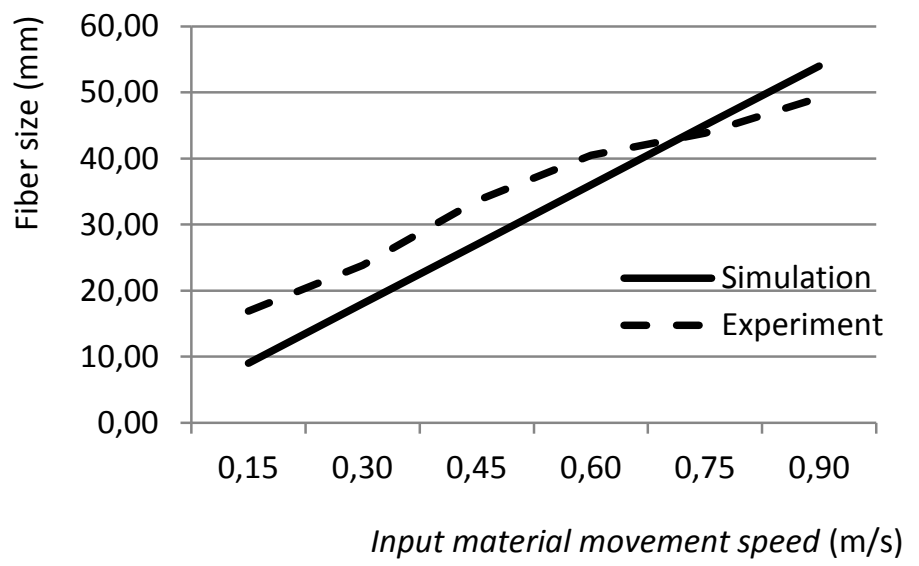

Figure 9: The difference between simulation and real data at 500 spins of the chipping drum.

\section{CONCLUSIONS}

In this paper definitions have been produced following research work on computer simulations and the experimental real testing of wood fiber production, regarding differences 
between the characteristics of a computer set wood fraction and the actually produced fraction during wood fiber production.

Individual relations between two sets of complex working technological parameters were researched. It was determined that the desired output fraction of wood fibers is greatly influenced by the variation of an individual changeable technological parameter.

The actual ratio between the number of the main chipping drum spins and the movement of the input material was determined by analytically comparing the computer simulation results and real testing. Thus, when varying the speed of raw material movement from 0,15 to $0,90 \mathrm{~m} / \mathrm{s}$ and keeping the same chipping drum spin number, the average size of wood fibers changes. At a certain chipper configuration the average size of wood fibers reaches the theoretical size that was determined by the computer simulation. At 500 spins of the chipping drum per minute this occurs when raw material movement speed is $0,72 \mathrm{~m} / \mathrm{s}$ (Fig. $9-$ intersection point). At 450 spins of the chipping drum per minute the experimental results meets the simulation results at raw material movement speed of $0,75 \mathrm{~m} / \mathrm{s}$, while at 550 spins of the chipping drum per minute the raw material movement speed that gives the same result at the experiment and at the simulation is slightly lower and is equal to $0,58 \mathrm{~m} / \mathrm{s}$.

It is to be noted that these findings are true when hard wood is used as raw material like in the experiments presented in this paper. Soft wood has very different mechanical cutting characteristics. With soft wood as raw material, the ration between theoretical values, determined by the computer simulation, and the actual size structure of wood fibers would probably be different.

In further research, the influences of technological, constructional, and material parameters should be discovered in more detail by finding their inter-dependences and by producing a decision model [24] that will support the selection of more suitable working parameters (knife form, chopping speed, moving speed, sieve size, etc.) considering known material characteristics regarding the inputted material (wood type, its moisture, structure, etc.) and given requirements (chips quality, their sizes and forms, special requirements for combustible installation, etc.).

\section{ACKNOWLEDGEMENTS}

The experimental work was done at the KGS Krajnc d.o.o. Company, where most of the real experiments regarding wood chip production and all the necessary analyses were carried out and the material parameters of the produced wood fraction defined.

The operational part was financed by the European Union, European Social Fund. This operation was implemented within the framework of the Operational Programme for Human Resources Development for the Period 2007-2013, Priority axis 1: Promoting entrepreneurship and adaptability, Main type of activity 1.1.: »Experts and researchers for competitive enterprises.«

\section{REFERENCES}

[1] CEN/TS 14961 (2005). Solid Biofuels - Fuel specification and classes, CEN/TC 335, Solid Biofuels, 40

[2] Hribernik, A.; Kegl, B. (2009). Performance and exhaust emissions of an indirect-injection (IDI) diesel engine when using waste cooking oil as fuel, Energy Fuels, Vol. 23, No. 3, 1754-1758, doi:10.1021/ef800986w

[3] Spinelli, R.; Nati, C.; Sozzi, L.; Magagnotti, N. (2011). Physical characterization of commercial wood chips on the Italian energy market, Fuel, Vol. 90, No. 6, 2198-2202, doi:10.1016/j.fuel. $\underline{2011.02 .011}$ 
[4] Raczynski, S. (2011). Uncertainty, dualism and inverse reachable sets, International Journal of Simulation Modelling, Vol. 10, No. 1, 38-45, doi:10.2507/IJSIMM10(1)4.180

[5] Uhmeier, A. (1995). Some fundamental aspects of wood chipping, TAPPI Journal, Vol. 78, No. $19,79-86$

[6] Abdallah, R.; Auchet, S.; Méausoone, P. J. (2011). Experimental study about the effects of disc chipper settings on the distribution of wood chip size, Biomass \& Bioenergy, Vol. 35, 843-852, doi:10.1016/j.biombioe.2010.11.009

[7] Hartler, N. (1986). Achievement and significance of optimal chip quality, TAPPI Journal, Vol. 79, No. 2, 259-264

[8] Merhar, M.; Bucar, B. (2012). Cutting force variability as a consequence of exchangeable cleavage fracture and compressive breakdown of wood tissue, Wood Science and Technology, Vol. 46, No. 5, 965-977, doi:10.1007/s00226-011-0457-4

[9] Spinelli, R.; Hartsough, B. (2001). A survey of Italian chipping operations, Biomass \& Bioenergy, Vol. 21, No. 6, 433-444, doi:10.1016/S0961-9534(01)00050-2

[10] Acko, B.; McCarthy, M.; Haertig, F.; Buchmeister, B. (2012). Standards for testing freeform measurement capability of optical and tactile coordinate measuring machines, Measurement science and technology, Vol. 23, No. 9 (Article number: 094013), doi:10.1088/0957$\underline{0233 / 23 / 9 / 094013}$

[11] Hellström, L. M.; Gradin, P. A.; Carlberg, T. (2008). A method for experimental investigation of the wood chipping process, Nordic Pulp \& Paper Research Journal, Vol. 23, No. 3, 339-342, doi: 10.3183/NPPRJ-2008-23-03-p339-342

[12] Nati, C.; Spinelli, R. (2010). How blade wear of chippers can affect fuel consumption and wood chip size distribution, Forest engeneering: Meeting the Needs of the Society and the Environment, FORMEC 2010, 1-7

[13] Kaban, A. K.; Othman, Z.; Rohmah, D. S. (2012). Comparison of dispatching rules in job-shop scheduling problem using simulation: a case study, International Journal of Simulation Modelling, Vol. 11, No. 3, 129-140, doi:10.2507/IJSIMM11(3)2.201

[14] Polajnar, A.; Vujica-Herzog, N.; Buchmeister, B.; Jevsnik, S. (2012). Strains and stresses of workers caused by exposure to noise, Collegium Antropologicum, Vol. 36, No. 3, 899-909

[15] Jasinskas, A.; Ulozevičiute, I.; Šarauskis, E.; Sakalauskas, A.; Puskunigis, M. (2001). Determination of energy plant chopping quality and emissions while burning chaff, Biosystem Engineering, Special Issue 1, 49-61

[16] Naimi, L. J.; Sokhansanj, S. (2006). Cost and performance of woody biomass size reduction for energy production, CSBE/SCGAB Annual Conference, 1-13

[17] Timmons, D.; Mejía, C. V. (2010). Biomass energy from wood chips: Diesel fuel dependence?, Biomass and Bioenergy, Vol. 34, No. 9, 1419-1425, doi:10.1016/j.biombioe.2010.04.010

[18] Nati, C.; Spinelli, R.; Fabbri, P. (2010). Wood chips size distribution in relation to blade wear and screen use, Biomass and Bioenergy, Vol. 34, No. 5, 583-587, doi:10.1016/j.biombioe. $\underline{2010.01 .005}$

[19] Spinelli, R.; Magagnotti, N.; Paletto, G.; Preti, C. (2011). Determining the impact of some wood characteristics on the performance of a mobile chipper, Silva Fennica, Vol. 45, No. 1, 85-95

[20] Spinelli, R., Magagnotti, N. (2010). A tool for productivity and cost forecasting of decentralised wood chipping, Forest Policy and Economics, Vol. 12, No. 3, 194-198, doi:10.1016/j.forpol. 2009.10.002

[21] Hackenschmidt, R.; Alber-Laukant, B.; Rieg, F. (2011). Simulating nonlinear materials under centrifugal forces by using intelligent cross-linked simulations, Strojniski vestnik - Journal of Mechanical Engineering, Vol. 57, No. 7-8, 531-538, doi:10.5545/sv-jme.2011.013

[22] Spinelli, R.; Visser, R. J. M. (2009). Analyzing and estimating delays in wood chipping operations, Biomass and Bioenergy, Vol. 33, No. 3, 429-433, doi:10.1016/j.biombioe. 2008.08.003

[23] Hartmann, H.; Böhm, T.; Jensen, P. D.; Temmerman, M.; Rabier, F.; Golser, M. (2006). Methods for size classification of wood chips, Biomass and Bioenergy, Vol. 30, 944-953, doi:10.1016/j.biombioe.2006.06.010

[24] Novak, M. (2012). Computer aided decision support in product design engineering, Tehnicki vjesnik - Technical Gazette, Vol. 19, No. 4, 743-752 